\title{
Residual stress mapping by micro x-ray diffraction: application to the study of thin film buckling
}

(Cartographie des contraintes résiduelles par diffraction $\mathrm{X}$ en micro faisceau : Application à l'étude des décollements spontanés de films minces supportés)

\author{
P. Goudeau and P. Villain
}

Laboratoire de Métallurgie Physique, UMR 6630 CNRS

Université de Poitiers, SP2MI, Téléport 2, Bd M. et P. Curie

BP 30179, F-86962 Futuroscope Chasseneuil cedex

N. Tamura, R.S. Celestre and H. Padmore

Advanced Light Source, Lawrence Berkeley National Laboratory

1 Cyclotron Road, MS 2-400, Berkeley, CA, 94270, USA

Corresponding author: $\quad$ P. Goudeau Tel. : 0549496726

Fax : 0549496692

e-mail : Philippe.Goudeau@univ-poitiers.fr 


\begin{abstract}
Thin films deposited by Physical Vapour Deposition techniques on substrates generally exhibit large residual stresses which may be responsible of spontaneous detachment of the film from its substrate and in the case of compressive stresses, thin film buckling. Although these effects are undesirable for future applications, one may take benefit of it for thin film mechanical properties investigation. Since the 80's, a lot of theoretical works have been done to develop mechanical models with the aim to get a better understanding of driven mechanisms giving rise to this phenomenon and thus to propose solutions to avoid such problems. Nevertheless, only a few experimental works have been done on this subject to support these theoretical results and nothing concerning local stress/strain measurement mainly because of the small dimension of the buckling (few tenth $\mu \mathrm{m}$ ). This paper deals with the application of micro beam x-ray diffraction available on synchrotron radiation sources for stress/strain mapping analysis of gold thin film buckling.
\end{abstract}

\begin{abstract}
Résumé : Les films minces déposés par des techniques de dépôt physique sous vide sur substrats présentent généralement des contraintes résiduelles très élevées qui peuvent être responsables du délaminage spontané du film et dans le cas de contraintes de compression, de l'apparition de cloques. Bien que ces décollements soient indésirables pour les applications technologiques futures, ils peuvent être mis à profit pour analyser les propriétés mécaniques locales dans ces systèmes. Depuis le début des années 80 , un grand nombre d'études théoriques ont permis de développer des modèles dans le soucis de mieux comprendre ces phénomènes de flambage. Néanmoins, la validation de ces modèles repose sur une confrontation avec des études expérimentales qui demeurent jusqu'à présent très rares. Ainsi, les champs de déformations associés à ces structures de décollements n'ont pas été déterminés du fait principalement de la faible taille des objets à analyser (quelques dizaines de microns). Cet article présente les premières expériences de diffraction des rayons $\mathrm{X}$ en micro faisceau réalisées sur une source de rayonnement synchrotron pour cartographier les déformations/contraintes associées à une cloque sur un film d'or.
\end{abstract}

\title{
1. INTRODUCTION
}

The development of thin films for industrial applications is constantly increasing because deposition techniques provide new class of materials which are impossible to obtain with classical elaboration processes. The structure which develops during thin film growth is tightly controlled by the deposition process. Thin films deposited by sputtering technique on non epitaxial substrates are often nanocrystallines which confers to the film very interesting properties. Depending on deposited atom energy, thin films adherent to bulk substrates are often in a tensile or compressive residual stress state which may affect their physical properties and reduce their life time.

In the case of thin films deposited at room temperature by direct ion beam sputtering, biaxial compressive residual stresses in the sample plane and interstitial defects in the unit cell are generally observed. The stress magnitude is often very high (larger than the elastic limit of the same material in the bulk state) and thus spontaneous delamination phenomenon such as buckling (2D) or wrinkling (1D) may appear for a critical film thickness (relaxation of the stored elastic energy) when extracting the sample out side the deposition chamber [1-4]. Although a lot of theoretical works have been done [5] to develop mechanical models and calculations (elasticity of thin plates, fracture mechanic, finite element, analytical calculation) with the aim to get a better understanding of driven mechanisms giving rise to this 
phenomenon, only a few experimental works [1-2] have been done on this subject to support these theoretical results and nothing concerning local stress/strain measurement mainly because of the small dimension of the buckling (few tenth $\mu \mathrm{m}$ ).

In this paper, we propose to use micro beam x-ray diffraction ( $\mu$-XRD) available on synchrotron radiation sources as a local probe (spatial) for stress/strain analysis of thin film buckling. The main objectives of this study are to apply $\mu$-XRD (i) for determining macro residual stresses at the top of the buckle (comparison with adherent region on the film) in different systems (W, Mo, Au on silicon) and (ii) step for scanning the buckling with the smallest x-ray beam size in order to realize macro stress mapping [6].

\section{SPONTANEOUS BUCKLING: GOLD FILMS}

$630 \mathrm{~nm}$ thick gold films deposited on silicon (100) substrates (covered with native oxide) have been chosen for these measurements. This material is widely used for microelectronic compounds such as Micro ElectroMechanical (MEMS) systems, a good candidate for X-ray diffraction because of its high Z atomic number and presents a very low adhesion on silicon substrates. Furthermore, thick gold films deposited by ion beam sputtering on silicon wafers show specific two dimensional buckles with large sizes and simple shapes (spherical). The delamination of the thin film is evidenced on figure 1 (a) and an individual buckle is shown on figure 1 (b); its shape corresponds to a portion of a sphere.

Wang and Evans [7] have established a simple relation ship between the width L and the height $\delta$ of the 2D buckling from which the residual stresses $\sigma$ may be estimated using in first approximation elastic constants of the bulk gold material (Young Modulus E=80.2 GPa and Poisson's ratio v=0.42):

$$
\mathrm{L}=\mathrm{A} \delta
$$

Where $\mathrm{A}=\left((4 / \sigma)^{*} \mathrm{E}_{\mathrm{f}} / 1-v \mathrm{f}^{2}\right)^{1 / 2}$ and $\left.\delta^{\prime}=(\delta / 1.25)^{2}+\left(1.22^{*} \mathrm{~h}^{2}\right)\right)^{1 / 2} ; \mathrm{h}$ is the film thickness.

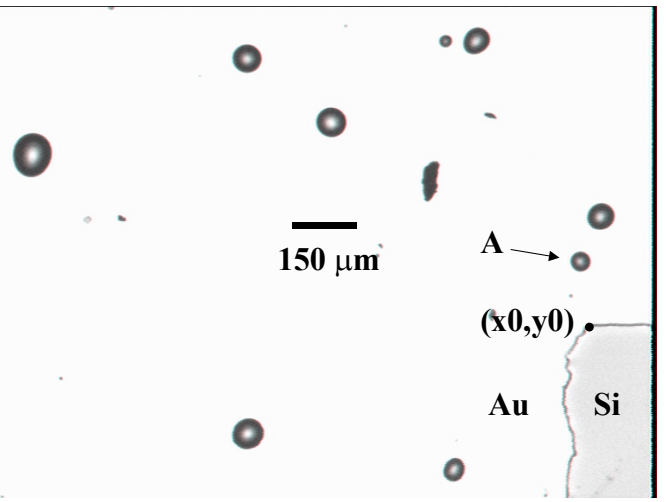

(a)

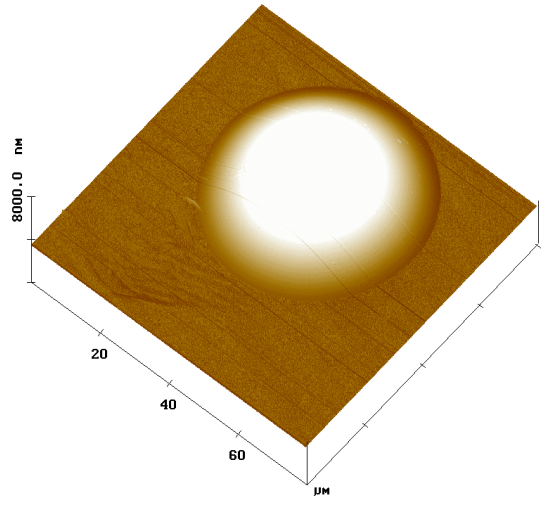

(b)

Figure 1. $630 \mathrm{~nm}$ gold film sputter deposited on Si substrate: (a) optical image of the sample surface and (b) Atomic Force Microscopy image of the buckle noted A in figure 1. (a).

Figure 1. Film d'or de $630 \mathrm{~nm}$ sur un substrat Si: (a) image optique de la surface du film et (b) observation AFM de la cloque notée A sur la figure 1. (a). 


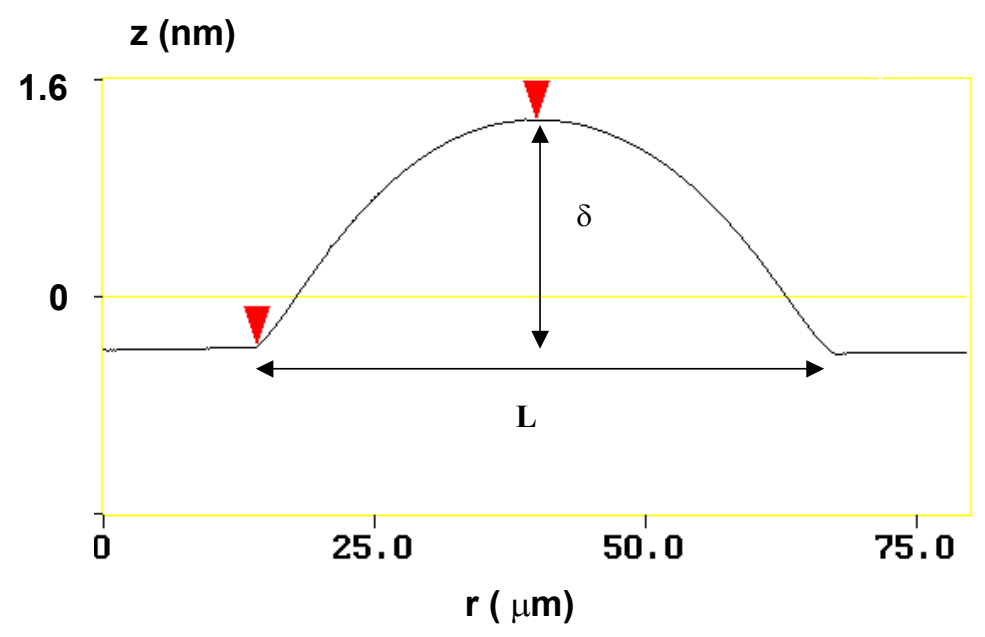

Figure 2. Cross section profile of the buckle noted $\mathrm{A}$ in figure 1. (a). The in plane width is around $40 \mu \mathrm{m}$ and the height of $1.7 \mu \mathrm{m}$.

Figure 2. Coupe transverse de la cloque notée A sur la figure 1. (a). La largeur dans le plan est de $40 \mu \mathrm{m}$ et la hauteur de $1,7 \mu \mathrm{m}$.

The data obtained by Atomic Force Microscopy on the different buckling sizes shown on figure 1 are plotted on figure 3. The stress value deduced from the slope of the linear fit is around $-290 \mathrm{GPa}(0.4 \%$ for strains when considering bulk elastic constants).

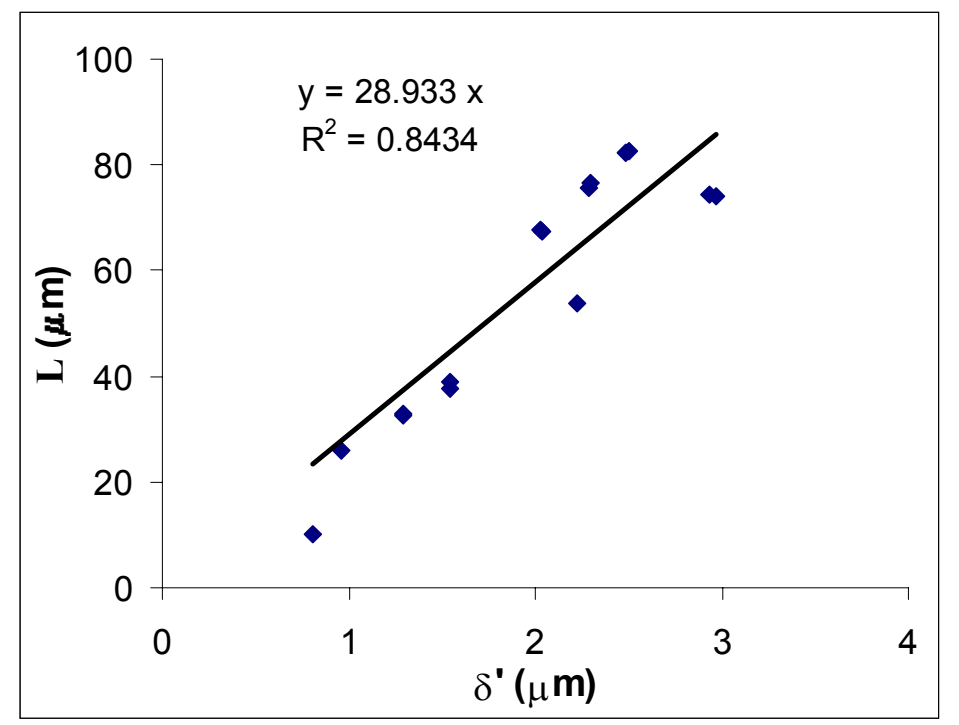

Figure 3. Variation of the buckle width $\mathrm{L}$ a function of the corrected height $\delta$ '. The straight line represents the linear fit.

Figure 3. Variation de la largeur L des décollements en fonction de la hauteur corrigée de l'épaisseur $\delta$ '. La ligne droite représente la régression linéaire.
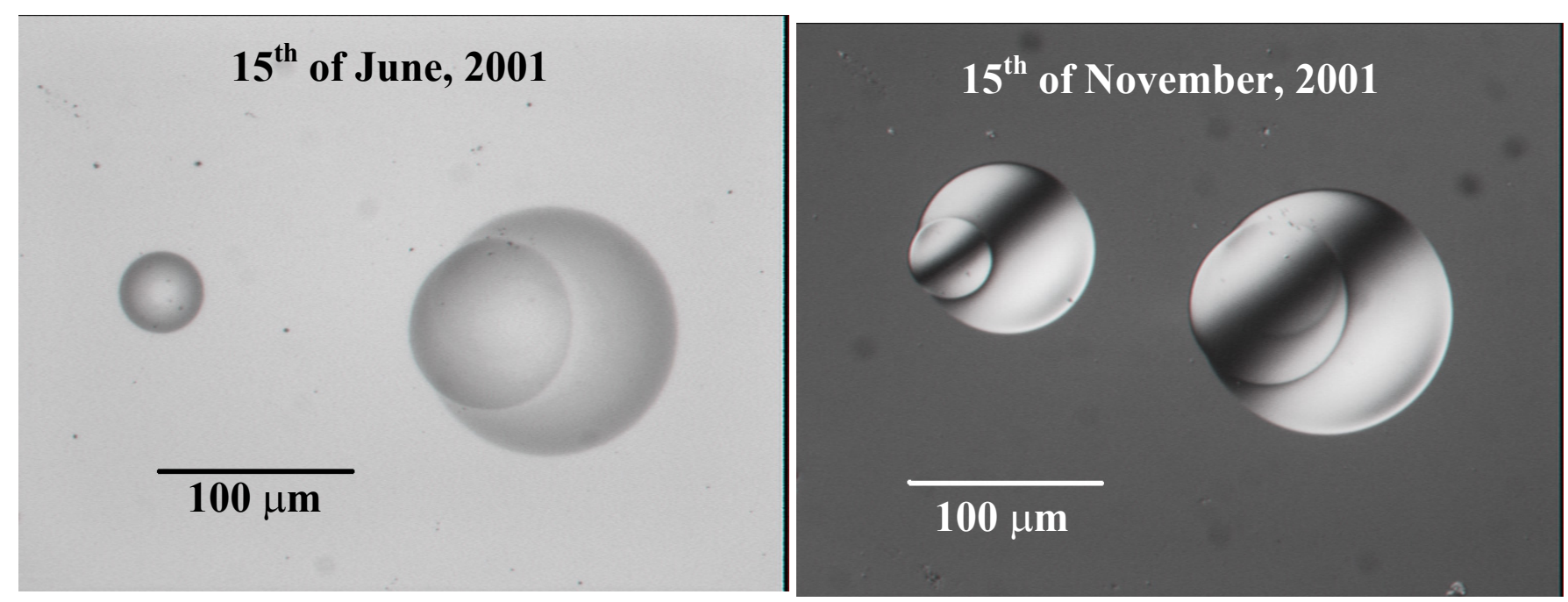

Figure 4. Evolution of thin film delamination after 5 months aging at room temperature.

Figure 4. Evolution des décollements au cours d'un vieillissement de 5 mois à température ordinaire. 
As shown in figure 4, the morphology of the delaminated zones is some times more complex (double sphere) and a possible evolution of blister configuration at room temperature may be observed with time.

\section{MACRO STRESS ANALYSIS BY X-RAY DIFFRACTION}

Among the most widely used method for determining the stress level in thin films, x-ray diffraction (XRD) is phase selective and the unique non destructive technique which allows to determine both the mechanical and microstructural state of the diffracting phases. Indeed, the distance between atomic planes is used as an internal strain gauge. For polycrystalline samples, the measurement of the diffraction peak position shift using $\sin ^{2} \psi$ method allows to extract the stress tensor and the stress free lattice parameter [8]. However, x-ray diffraction is difficult to use in low dimensional systems because the diffracted intensities are weak due to the reduced thicknesses and nanocrystalline character of such materials. These problems may be solved using intense x-ray sources such as synchrotron radiation (S.R.). In addition to the high flux characteristic of S.R. facilities, the wide wavelength spectra and the optics (micro beam) which are available on beam lines ( $3^{\text {rd }}$ generation SR only) allow to perform specific XRD experiments which are not possible with classical x-ray sources in laboratories.

The 7.3.3.1 Microdiffraction beam line [9] at Advanced Light Source of the Lawrence Berkeley National Laboratory [10] provides a reduced spot size less than $1 \mu^{2}$ (Kirkpatrick Baez mirrors) with high flux for white or monochromatic radiation (4-crystals channel cut monochromator: 6-14 KeV; see figure 5 and 6 ).

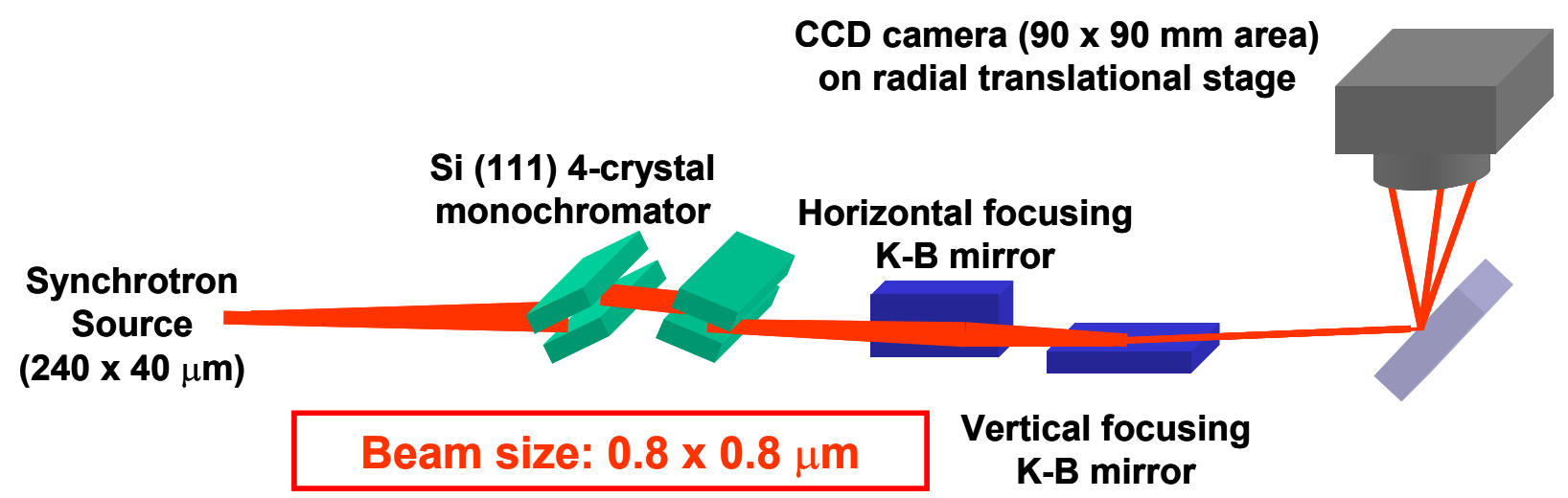

Figure 5. Schematic drawing of $\mu-X R D$ beam line 7.3.3.1 at the A. L. S. Berkeley - USA.

Figure 5. Représentation schématique de la ligne de lumière 7.3.3.1 de l'A.L.S. Berkeley - USA.

These performances are unique and perfectly adapted to our purpose. For comparison, the MicroFluorescence-Imaging-Diffraction group at ESRF has developed Bragg-Fresnel lens [11] which allow to get reduced spot size greater than 1 x $5 \mu \mathrm{m}^{2}$ with high flux for an higher energy range (up to $30 \mathrm{keV}$ ). A lot of XRD experiments have been done to investigate in bulk materials the mechanical properties of each individual grains [12-15]. In our samples, the grain size $(\leq 10 \mathrm{~nm})$ is smaller than the $\mathrm{x}$-ray beam one and macro-strains are of about $0.5-1 \%$. The diffraction pattern recorded with a 2D CCD detector is composed of different rings which allow to extract (using specific software - to be developed) the in-plane stress without any tilt of the samples (the $\psi$ description is contained in the $2 \mathrm{D}$ pattern and the angular resolution is enough to appreciate such large macro-strains). Accurate spatial spot localization on the sample surface is achieved from markers delimitating the region of interest. A precise goniometer allows XRD measurements in reflection mode and an X-Y translation stage is used for scanning the sample surface. 

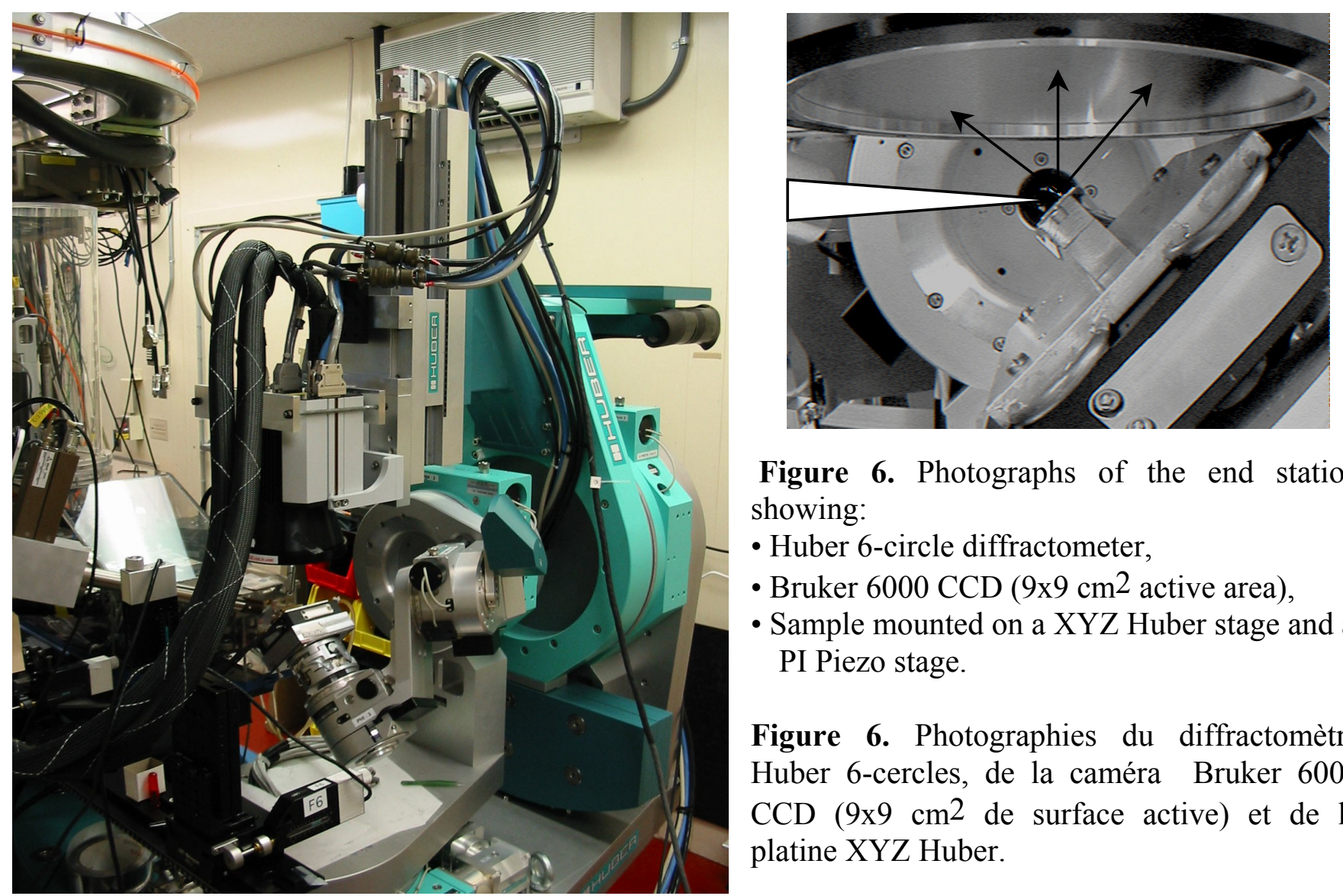

Figure 6. Photographs of the end station showing:

- Huber 6-circle diffractometer,

- Bruker $6000 \mathrm{CCD}\left(9 \mathrm{x} 9 \mathrm{~cm}^{2}\right.$ active area),

- Sample mounted on a XYZ Huber stage and a PI Piezo stage.

Figure 6. Photographies du diffractomètre Huber 6-cercles, de la caméra Bruker 6000 CCD (9x9 $\mathrm{cm}^{2}$ de surface active) et de la platine XYZ Huber.

\section{RESULTS}

Classical x-ray diffraction measurements have been performed over the whole film surface i.e. adherent and delaminated regions with $\mathrm{Cu} \mathrm{K}_{\alpha 1}$ wavelength. As shown on figure 7, the gold film presents a $<111>$ fibre texture.
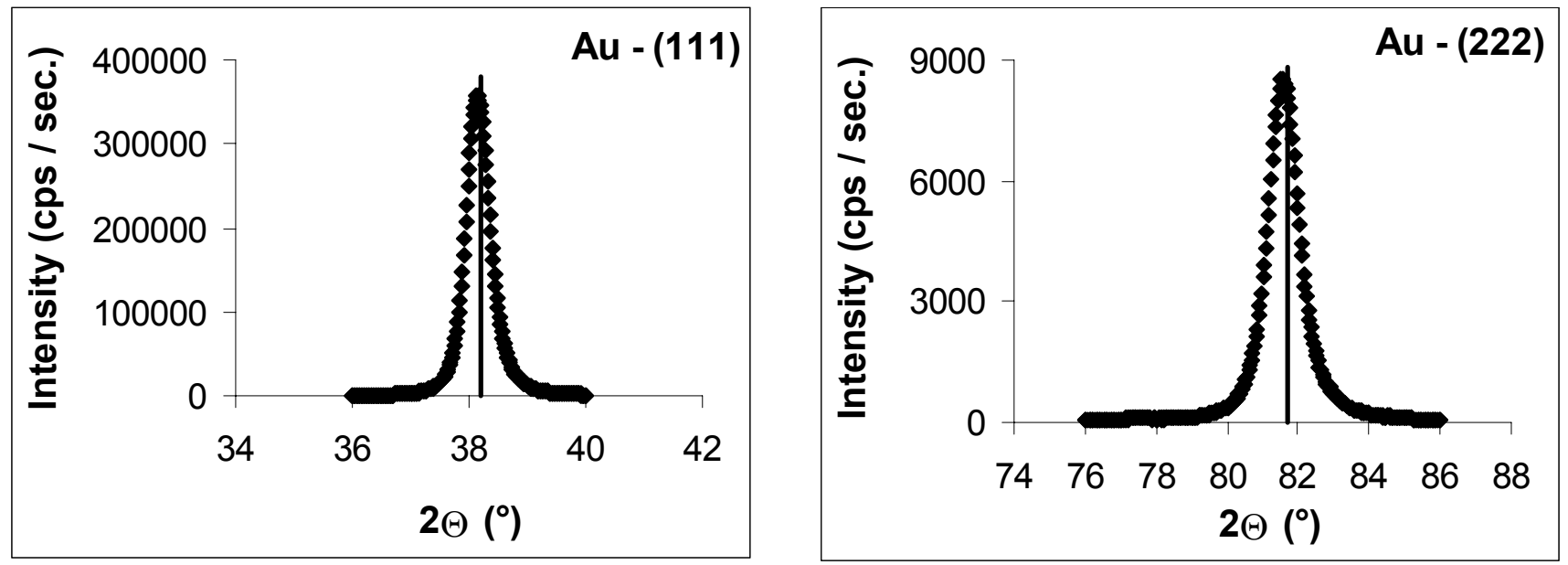

Figure 7: X-ray diffraction diagrams recorded in $\Theta-2 \Theta$ mode on a D5005 Bruker AXS diffractometer with standard input and output slits.

Figure 7: Diagrammes de diffraction $X$ enregistrés en mode $\Theta-2 \Theta$ sur un diffractomètre D5005 de la Société Bruker AXS avec des fentes standards d'entrée et de sortie. 


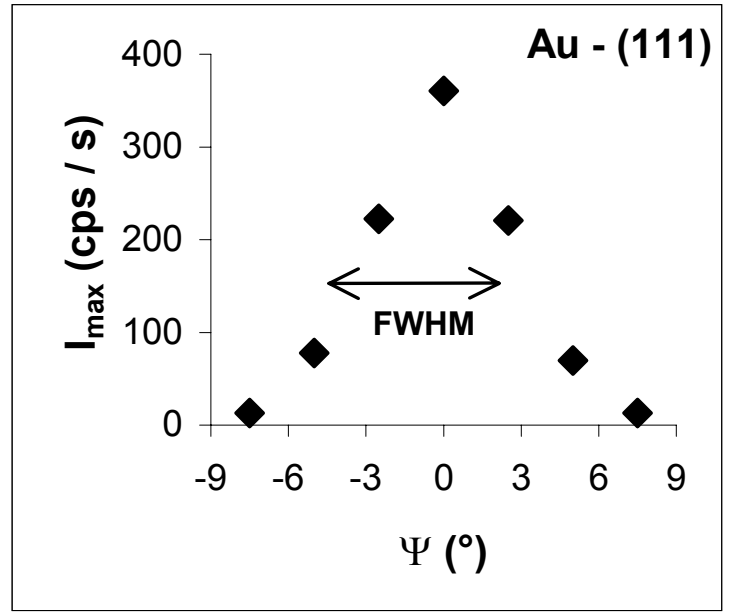

Figure 8: Rocking curve measurements performed on (111) diffracting planes of the gold film with a specific diffractometer described in ref. [8]. Diffraction peak profiles have been recorded using a Position Sensitive Detector.

Figure 8: Variation du maximum d'intensité du pic de diffraction (111) du film d'or en fonction de l'angle $\psi$. Les mesures ont été réalisées à l'aide d'un montage spécifique [8] mettant en œuvre un détecteur à localisation linéaire.

A fibre axis disorientation of $+/-3^{\circ}$ is given by the Full Width at Half Maximum (FWHM) of the Rocking Curve measurements (figure 8). The grain size and the micro strains deduced from the Integral Width method applied to $\{111\}$ family planes are equal to $28 \mathrm{~nm}$ and $0.4 \%$ respectively. Furthermore, the lattice parameter value deduce from the (111) diffraction peak position $(0.4086 \mathrm{~nm})$ is larger than the bulk one (0.4078). This volume expansion in the growth direction may be explained by the presence of interstitial defects in the unit cell and also the influence of in plane compressive residual stresses.

Preliminary micro beam X-ray diffraction experiments have been successfully done in June 2001 on the buckle noted $\mathrm{A}$ in figure 1. (a). The position of the buckle $(\mathrm{x}, \mathrm{y})$ is determined from the step corner coordinates $\left(\mathrm{x}_{0}, \mathrm{y}_{0}\right)$ which have been measured by $\mathrm{X}$-ray fluorescence (white beam). The absolute accuracy on the $(\mathrm{x}, \mathrm{y})$ position is better than $10 \mu \mathrm{m}$. Let us notice that this step on the silicon wafer has been realized during the film deposition for film thickness measurement using a mechanical profilometer.

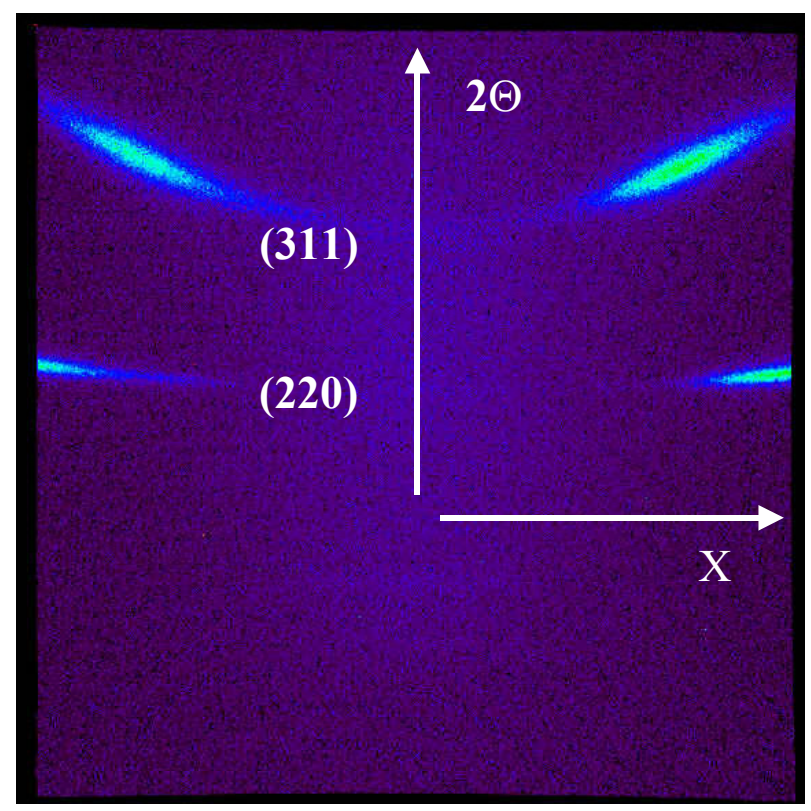

Figure 8: 2D X-ray diffraction diagram obtained on an adherent gold film region with an X-ray energy of $5.7 \mathrm{keV}$, a spot size on the sample of $3 \times 3 \mu \mathrm{m}^{2}$ and a recording time of $300 \mathrm{~s}$.

Figure 8: Diagramme de diffraction 2D mesuré sur une région non décollée du film d'or avec une énergie de 5,7 keV, une taille de faisceau sur échantillon de $3 \times 3$ $\mu \mathrm{m}^{2}$ et un temps de comptage de 300 secondes.

The calibration of the $2 \mathrm{D}$ diffraction diagram is done from the diffraction of the single crystal silicon substrate using white x-ray beam. The diffraction pattern obtained in an adherent (flat) region of the gold film is shown in figure 8 . The $2 \Theta$ angular position of the (311) diffraction ring is around $120^{\circ}$ for the considered photon energy and sample configuration; the $X$ angular range is $0- \pm 55^{\circ}$. Because of the $<111>$ texture of the film, we observe maximum intensities on each two rings for particular pole directions X. During the scan of the buckle A in figure 1. (a) with a $10 \mu \mathrm{m}$ step, the position of the two maximum intensities $\left(\mathrm{X}^{+}\right.$and $\left.\mathrm{X}^{-}\right)$moves along the ring because of the rotation of the normal to the film surface around $\mathrm{x}$ and $\mathrm{y}$ axis of the sample surface. Thus, from the diffraction pattern, one may deduce the 
position of the beam on the buckle and the corresponding strains in this region. A comparison between the diffraction diagrams obtained in flat regions and at the top of the buckle indicates a stress relaxation. Considering the bulk elastic constant of gold, the calculated stress value varies from - 400 to -10 MPa with a stress relaxation evolution following the cross section profile of the buckle given in figure 2 .

\section{CONCLUDING REMARKS}

A complete interpretation of the data is still under progress because specific tools and methodologies have to be applied for diffraction pattern analysis. Accuracy and sensibility are the two main points to be considered for strain variation during the scan. In addition, Finite Element Calculation have been engaged for such spherical gold buckles in order to interpret the measured stress map associated to the 2D buckling. In a same way, wrinkles with smaller dimension observed for tungsten and molybdenum films have also been analyzed using the same technique but the scan measurement is more difficult due to the more complex shape of delamination and the rather small dimension of buckling compare to the 2D gold one.

Further experiments in October 2002 will concern not only metallic thin films but also structural biomaterials such as diamond coatings on Titanium based alloys which are promising candidates for medical prostheses and where very high thermal compressive stresses (up to $-6 \mathrm{GPa}$ ) may be observed and Micro ElectroMechanical Systems (MEMS).

\section{Acknowledgement}

The authors would like to thank M. Drouet for thin film deposition and C. Coupeau for Atomic Force Microscopy observations.

The Advanced Light Source is supported by the Director, Office of Science, Office of Basic Energy Sciences, Materials Sciences Division, of the U.S. Department of Energy under Contract No DE-AC0376SF00098 at Lawrence Berkeley National Laboratory.

\section{References}

1. Talea M., Boubeker B., Cleymand F., Coupeau C., Grilhé J., Goudeau Ph., Materials letters 41181 (1999).

2. Coupeau C., Naud J.-F., Cleymand F., Goudeau P., Grilhé J., Thin Solid Films 353194 (1999).

3. Branger V., Coupeau C., Goudeau P., Boubeker B., Badawi K.F., Grilhé J., J. of Materials Science Letters 19353 (2000).

4. Boubeker B., Talea M., Goudeau Ph., Coupeau C., Grilhé J., Materials Characterization 4533 (2000).

5. Gioia G. et Ortiz M., Advances in Applied Mechanics 33119 (1997).

6. Goudeau P. in PHOTOMECANIQUE 2001 edited by Y. Bertaud et col. (GAMAC, Paris, 2001) p.87.

7. Wang J.-S. and Evans A.G., Acta Mater. 46 (14) 4993 (1998)

8. Branger V., Pelosin V., Goudeau P., Badawi K.F., High Temp. Material Processes 2419 (1998).

9. MacDowell A.A., Celestre R.S., Tamura N., Spolenak R., Valek B., Brown W.L., Bravman J.C., Padmore H.A., Batterman B.W. and Patel J.R., Nuclear Instruments and Methods in Physics Research A 467-468 936 (2001).

10. http://www-als.lbl.gov

11. Snigirev A., Rev. Sci. Instrum. 66 (2) 2053 (1995).

12. Biermann H., Grossmann B.V., Mechsner S., Mughrabi H., Ungar T., Snigirev A., Snigireva I., Souvorov A., Kocsis M., Raven C., Scripta Materiala 37 (9) 1309 (1997). 
13. Castelnau O., Ungar T., Drakopoulos M., Snigirev A., Snigireva I., Schroer C., Chauveau T., Bacroix B., Key Engineering Materials 177-180 147 (2000).

14. Castelnau O., Béchade J.L., Brenner R., Chauveau T., Bacroix B., Ungar T., Drakopoulos M., Snigirev A., Snigireva I. in Advances in mechanical behaviour, plasticity and damage, Proceeding of EUROMAT 2000, Elsevier ed. 2911 (2000).

15. Maire E., Owen A., Buffiere J.-Y., Withers P.J., Acta Mater. 49153 (2001). 